DOI:

Recepción: 07 / 11 / 2016

Aceptación: 15 / 02 / 2017

Ciencias económicas y empresariales

Publicación: 15 / 05 / 2017

\title{
Los procesos migratorios y su repercusión en las economías nacionales
}

\author{
Migration processes and their impact on national economies
}

Processos de migração e seu impacto sobre as economias nacionais

\author{
Ernesto Gutiérrez-Vallejo ${ }^{\mathrm{I}}$ \\ ernestogutierrez.10@hotmail.es \\ José M. Gracia-Chancay II \\ chiqui202020@hotmail.com \\ Jefferson E. Quiñonez-Mosquera III \\ jeffcheton@hotmail.com
}

Correspondencia: ernestogutierrez.10@hotmail.es

- Magister en Gerencia de Proyectos Educativos y Sociales, Especialista en Diseño de Proyectos, Diplomado Superior en Liderazgo y Gerencia, Diploma Superior en Práctica Docente Universitaria, Doctor en Ciencias de la Educación con Especialidad en Investigación Educativa, Licenciado en Ciencias de la Educación Especialidad Filosofía y Ciencias Socioeconómicas.

" Magister en Docencia mención Gestion en Desarrollo de Currículo, Licenciado en Ciencias de la Educación, Profesor de Segunda Enseñanza en la Especialización de Filosofía y Ciencias Socio Económicas.

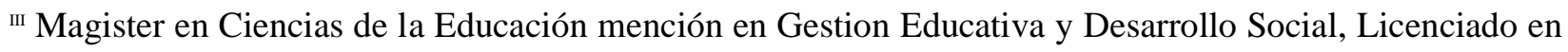
Ciencias de la Educación, Profesor de Segunda Enseñanza en la Especialización de Filosofía y Ciencias Socio Económicas. 


\section{Resumen}

En el siglo XXI, las migraciones se han intensificado y mundializado: cada vez es más elevado el número de países que significativamente se ven involucrados en las migraciones internacionales, esto se debe al avance tecnológico y las comunicaciones que han reducido los tiempos de intercambios y distancias en el mundo. El mundo global coloca el fenómeno de la migración con especiales dimensiones, lo que obliga a considerar una política compartida al respecto, alejando paulatinamente las acciones unilaterales. Esta realidad constituye un desafío para diversos ámbitos que deben establecer políticas basadas en principios comunes, más aun cuando se considera la migración vinculada a los derechos humanos y adquiere protagonismo la dimensión normativa internacional y no sólo la doméstica.

Palabras clave: migración; procesos migratorios; economías nacionales.

\section{Abstract}

In the twenty-first century, migrations have intensified and globalized: the number of countries that are significantly involved in international migration is increasing, this is due to technological advances and communications that have reduced times of exchanges and distances in the world. The global world places the phenomenon of migration with special dimensions, forcing it to consider a shared policy in this regard, gradually moving away unilateral actions. This reality is a challenge for diverse areas that must establish policies based on common principles, even more when considering the migration linked to human rights and takes on the international normative dimension, not just the domestic one.

Keywords: migration; migration processes; economies.

\section{Resumo}

No século XXI, a migração se intensificou e globalizado: é cada vez mais aumentou o número de países que significativamente estão envolvidos na migração internacional, isso é devido ao avanço tecnológico e comunicações reduziram os tempos de trocas e distâncias no mundo. O mundo global coloca o fenómeno da migração com dimensões especiais, o que requer a consideração de uma política compartilhada em relação gradualmente se afastando ações unilaterais. Esta realidade é um desafio para muitas áreas para estabelecer políticas baseadas em 
princípios comuns, ainda mais quando se considera a migração ligada aos direitos humanos e do direito internacional leva dimensão centro do palco e não apenas nacional.

Palavras chave: migração; processos de migração; economias nacionais.

\section{Introducción}

Las migraciones son una constante histórica, pero en función del tiempo varían sus causas, sus características y sus consecuencias. Los antropólogos, las consideran una universal cultural. La primera ciencia en estudiar las migraciones fue la geografía humana, a los que posteriormente se sumaron otras como la psicología, la historia, la antropología, etc.

En el siglo XXI, las migraciones se han intensificado y mundializado: cada vez es más elevado el número de países, que significativamente se ven involucrados en las migraciones internacionales, esto se debe al avance tecnológico y las comunicaciones que han reducido los tiempos de intercambios y distancias en el mundo.

La migración es un proceso que está motivado por diversas causas, entre ellas se encuentran la realidad política existente en el país, que producen la salida forzada de las personas, producto de una persecución o riesgo de ella y las situaciones económicas, que inducen a buscar nuevos horizontes para satisfacer necesidades básicas o mejorar las condiciones de vida.

El mundo global coloca el fenómeno de la migración con especiales dimensiones, lo que obliga a considerar una política compartida al respecto, alejando paulatinamente las acciones unilaterales.

Esta realidad constituye un desafío para diversos ámbitos que deben establecer políticas basadas en principios comunes, más aun cuando se considera la migración vinculada a los derechos humanos y adquiere protagonismo la dimensión normativa internacional y no sólo la doméstica.

En el marco de la información y análisis deben situarse el desarrollo investigativo acerca de las contribuciones de los inmigrantes en diversos ámbitos. A este respecto, el tratamiento no es simétrico y es frecuente que se valore la contribución de determinadas migraciones, otras se ignoren y algunas sean asumidas con una visión negativa. Es un desafío académico incentivar los estudios, especialmente de los nuevos flujos de inmigrantes dando un enfoque más equilibrado.

El presente artículo dirige su mirada hacia algunas aproximaciones, en relación a los procesos migratorios y la influencia que ejercen estos en las economías nacionales. 


\section{Desarrollo}

De acuerdo a lo señalado por Verónica Cano y Magdalena Soffia, la migración debe entenderse “como proceso en la medida que el traslado de las personas, desde un país a otro implica un conjunto de factores causales, de desarrollo y consecuencias, tanto para la sociedad de origen como de destino. No se trata de una acción aislada y estática, sino que está inmersa en un entramado de relaciones sociales y circunstancias políticas y culturales que se van modificando continuamente en el tiempo".

En términos más amplios, que abarca tanto la migración interna como la internacional, se encuentran autores que la definen como "el hecho de atravesar la línea divisoria de una unidad política o administrativa durante un período mínimo de tiempo". Una definición de esta naturaleza del fenómeno, está en línea con la argumentación de que la distinción rígida entre migración nacional e internacional puede generar confusión y equivocación en el análisis.

A este respecto es pertinente la constatación de Castles, al indicar que la migración internacional puede producirse entre distancias cortas y entre pueblos con similares culturas, mientras existen migraciones internas que implican recorrer grandes distancias. Hay otras situaciones en que se describen como que "son las fronteras las que migran", convirtiendo a migrantes internos en internacionales. Un ejemplo de esto fue lo ocurrido con el desmembramiento de la Unión Soviética, que trajo consigo que antiguos migrantes internos quedaran como extranjeros en los estados que surgieron de las antiguas repúblicas que alcanzaron su independencia.

La Organización de Naciones Unidas (ONU), ha definido a un inmigrante como una persona que cambia su lugar de residencia, por un periodo de más de un año. Respecto a esta definición se ha destacado como positivo su simplicidad y coincidencia con el periodo - un año- que normalmente constituye la unidad de tiempo para la contabilidad demográfica, utilizada habitualmente en las estadísticas nacionales e internacionales.

Sin embargo, se ha criticado que esta definición no tenga en cuenta "la visión del país de destino ni la situación del potencial inmigrante, en particular sus derechos en lo relacionado con la duración posible de su estadía en el país, o con respecto al acceso a servicios públicos y transferencias". 
Cualquiera sea la definición de migración que se adopte, siempre estará presente la tensión entre el derecho de las personas, a asentarse donde ellas determinen y el que se asignan los estados de limitar o regular las condiciones del componente humano en función de su soberanía. Dicho derecho se manifiesta, de acuerdo a lo que recogen publicaciones de organizaciones internacionales, mediante la entrega de un permiso que, en caso de no ser permanente, es más o menos renovable en forma indefinida, aunque la renovación pueda estar sujeta a determinadas condiciones. El derecho a la residencia permanente propiamente tal se concede por lo general después de una cantidad de años de residencia en el país.

La mayor vulneración del derecho a permanecer, donde las personas determinen se da en la emigración obligada, toda vez que ellas, en razón de situaciones políticas, religiosas, raciales, étnicas u otras, se ven impedidas, incluso, de vivir en su propia patria, debiendo buscar un lugar de destino, en numerosos casos sin poderlo elegir. Al respecto es preciso tener presente que la noción de migración forzada en un sentido más amplio, no sólo incluye a refugiados y solicitantes de asilo territorial, sino a personas obligadas a trasladarse por razones distintas a las mencionadas, como por ejemplo las causadas por catástrofes.

Por su parte, la emigración voluntaria está motivada por la búsqueda de mejores condiciones de vida y, por tanto, implica la opción de dejar el país de origen, como también la elección del país de destino.

Desde el punto de vista del país receptor, puede distinguirse entre la inmigración inducida y la espontánea. La primera tiene lugar cuando por distintas razones existe una motivación en un país, para efectuar acciones de recepción de extranjeros, sea globalmente o respecto a estados determinados o regiones singularizadas, llegando en casos de manera selectiva a personas específicas, particularmente mirando su formación y/o especialización y su nacionalidad de origen. La segunda, vale decir la espontánea, normalmente escapa a la voluntad del estado receptor, toda vez que el lugar de destino es opción del migrante.

Dado la evolución internacional, el tema se ha incorporado con especiales caracteres al debate público. Colabora en esta perspectiva el desarrollo de las comunicaciones y las mayores posibilidades de desplazamiento. El análisis debe efectuarse no con énfasis coyuntural, sino que es preciso enmarcarlo históricamente y visualizar su desarrollo, particularmente enfocado en la 
naturaleza de las personas que viven el proceso migratorio. Para fortalecer dicho análisis es preciso mejorar la información sobre este fenómeno internacional, por ello hay que tener en cuenta lo señalado en estudios que indican que la falta de ella "es un serio obstáculo a la formulación e implementación de políticas que beneficien a los migrantes, a sus familias y a los países tanto de origen como de destino". Esta percepción es acompañada por expresiones que afirman que la información confiable, acompañada de datos comparables entre países y un monitoreo regular de los movimientos y las políticas son elementos esenciales para avanzar en la comprensión y la gestión de la migración.

\section{Modelos de emigración}

- Modelo de elección individual: desde una perspectiva microeconómica, la elección individual de emigrar por parte de una persona se encuentra basada en el objetivo de maximizar su bienestar. Es por esto que la persona compara la situación actual con la futura y, dependiendo de los costes y beneficios tomará la decisión de emigrar o no.

Tomando como indicador la decisión individual de emigrar, el proceso migratorio se desarrolla mediante una tendencia que centra la decisión de emigrar tomando en cuenta el diferencial existente entre los ingresos del país, en el que se encuentra actualmente con respecto al país que se espera emigrar. Todaro (1976) y Hicks (1932), manifiestan que adicionalmente al diferencial de ingresos que contempla la persona que piensa en emigrar, existe en la persona ver cuál es la probabilidad de encontrar un trabajo en la zona a la cual se piensa emigrar.

- Modelo del capital humano y los flujos migratorios: este modelo trata de ir más allá, que el modelo de elección individual de emigrar. Parte de la posibilidad de calcular el valor actualizado neto de los rendimientos futuros ocasionados por el hecho de emigrar, comparándolos con los beneficios \& costes (incluyendo el factor síquico) a una tasa de descuento. Esta teoría trata como si se sacrificara una inversión en el tiempo presente, con el objetivo de obtener rendimientos adicionales en el futuro. De esta manera el individuo que emigra, le compensa realizar una inversión en capital humano en el momento actual, con el propósito de aumentar sus rendimientos en un futuro. Fueron Sajaastad, 1962; Becker, 1962; y Mincer, 1978 quienes en base a este modelo, obtuvieron conclusiones relevantes al momento de decidir si emigrar o no. 
Estos autores lograron mostrar que con un aumento en la edad, la probabilidad de emigrar cada vez tiende a cero debido a que los rendimientos de inversión en capital humano, descienden en el medio y largo plazo; es decir, que existe poco tiempo para percibir los beneficios de emigrar a un país por la avanzada edad, en la que se encuentra el individuo. Por otro lado, en el corto plazo aumenta el costo de oportunidad de abandonar la situación presente.

Otra variable tomada en cuenta en esta teoría, es el nivel de educación del emigrante. Mientras mayor sea el nivel de estudios de la persona que emigra dado una situación de desempleo en el país y también contemplando los beneficios poco significativos para la persona, existe una mayor probabilidad de que exista la posibilidad de migrar.

Por otro lado, aquellas variables que causen un aumento de los costes de migración (ya sea económicos o sicológicos) generan una probabilidad menor para la misma. Las variables contempladas en esta teoría son: distancia geográfica, la existencia o no de familiares en el lugar de destino, las cargas familiares (sobre todo si se tienen hijos en edad escolar), la asimetría de la información, la política migratoria en general y la legislación en los países de destino en particular.

Una variable que puede ser contemplada como causa para el aumento en los costos de emigración es el factor cultural. Ríos \& Rueda (2005), han demostrado en un estudio empírico para el Perú que la cultura del país, al cual se emigra es una variable significativa cuando se toma en cuenta la decisión de emigrar o no.

- La nueva economía de la migración laboral: esta teoría fue propuesta por Oded Stark (1991). La inspiración inicial para el enfoque de la "nueva economía de la migración laboral" proviene del concepto de la nueva economía política (New Political Economy) de la economía de la familia, que analiza los incentivos y las implicaciones de las decisiones tomadas por los miembros de la familia en el sentido de maximizar sus ganancias. El concepto de la nueva economía de la migración laboral, trabaja con la idea de contratos implícitos dentro de la familia, que incluye no solamente factores económicos, sino que intenta también incluir el momento de las relaciones afectivas y también trabaja con la influencia del horizonte temporal de la migración.

Los Factores son los siguientes: 
- Es posible modelar la relación familiar entre migrantes y no-migrantes, como un contrato de seguro mutuo implícito. Aquí migración y envío de remesas tienen la función de una distribución mejor del riesgo de ganancia de ingreso. Dado que la probabilidad de una crisis simultánea en dos países diferentes es relativamente baja, la familia vista, como un todo, tiene una probabilidad más alta de obtener constantemente por lo menos un ingreso.

- La otra vertiente modela la migración laboral, como un contrato implícito de crédito, donde la familia funciona como un banco que prefinancia la migración por inversiones en la educación del hijo (o de la hija) y que por vía de las remesas recibe este crédito de vuelta.

- Un tercer motivo siempre a ser considerado es el altruismo, el amor a la familia. Las remesas motivadas por altruismo tienen la tendencia de crecer en tiempos de crisis en el país receptor de las remesas (y viceversa), así como también deberían crecer con el ingreso del emigrante.

- El horizonte temporal pesa en las motivaciones del remitente. Cuanto más corta es la temporada migratoria, mayores deberían ser las remesas, ya que se efectuarán solamente las inversiones más necesarias en el país destino de la migración. Si la migración es duradera, es decir, la persona emigrante se decide por una migración definitiva, las remesas van a disminuir significativamente y pueden hasta cesar. Lo que se observa también en sociedades con larga experiencia migratoria es una migración en oleadas. Esto significa que es siempre la generación activa la que emigra y sostiene la familia que se queda en el país de origen, pero vuelve en el momento de jubilación, manteniendo de esta forma un sistema de transferencias intergeneracionales vía migración y remesas.

Para González, la migración puede ser una oportunidad para aprender de otros imaginarios, de otras tradiciones. "Gracias a los migrantes, la economía de Europa y Estados Unidos ha crecido ostensiblemente", señala. De esta forma, la migración debe ser reconocida como una fuerza positiva para el desarrollo.

\section{Migración y economía}

La salida de ciudadanos de un país reduce la presión de la fuerza laboral, pues en el mediano plazo produce disminución en el desempleo y aumento en el salario promedio. Pero también ocasiona pérdida en la mano de obra, que afecta la capacidad de producir bienes y servicios. El 
efecto es agravado si los migrantes cuentan con altos niveles de formación; pues el costo de perderlos es mayor.

Asimismo, los que migran envían remesas, y mediante estos recursos pueden aumentar la renta de los familiares en su país de origen.

Por parte de los países receptores, en su mayoría economías desarrolladas (EEUU y Europa), al recibir los flujos migratorios presentan efectos como: aumento en su fuerza laboral, que se traduce en aumentos del desempleo y en la presión de asistencia social, y pérdida de renta nacional por la emisión de remisas. De acuerdo con la ONU, los migrantes en países desarrollados envían anualmente 414.000 millones de dólares a sus países de origen.

\section{Impactos en la cultura}

No hay duda de que la migración, genera procesos de homogenización cultural a nivel internacional. Mediante el intercambio, los países receptores adoptan costumbres y patrones de consumo. De esta manera se plantea una relación bidireccional entre migración y comercio.

A medida que la integración comercial se profundiza, hay movilidad de factores como el trabajo, que conllevan a la convergencia de salarios de los trabajadores entre los países.

Cuando se mide el impacto económico de la migración, uno de los aspectos positivos es lo que gana el país de origen de los migrantes. Sin embargo, poco se revisa cuánto gana el país al que llegan.

Comúnmente se argumenta que la migración tiende a elevar en el país de destino, las tasas de desempleo y reducir los salarios de los trabajadores nativos. Lo primero debido a que los migrantes incrementan la oferta laboral y compiten por los puestos de trabajo con los trabajadores nativos y con ello algunos de éstos pueden ser desplazados. También se argumenta que los migrantes en general están más dispuestos a aceptar condiciones laborales inferiores, entre ellas, menos prestaciones laborales y menores remuneraciones, con lo que los trabajadores en el país de destino también pueden verse obligados a aceptar menores ingresos, lo cual ocasiona que en general los salarios se reduzcan.

En general, la emigración se suele observar de los países en vías de desarrollo a países desarrollados; estos últimos concentran el $60 \%$ de la migración mundial. Los países desarrollados 
tienden a presentar tasas de natalidad y mortalidad relativamente bajas, con lo cual se puede presentar en ellos un envejecimiento de la población, en términos relativos más acelerado.

En relación a los efectos positivos sobre la política fiscal y monetaria, en general, los flujos migratorios fluctúan en el mismo sentido que el ciclo económico. En épocas expansivas se aceleran y en épocas de recesión se reducen. Con ello pueden potenciar los efectos de la política fiscal y monetaria. Veamos por qué.

Si la migración incrementa la oferta de trabajo cuando más se requiere, contribuye a acelerar la velocidad a la que se expande la economía favoreciendo el quehacer de la política fiscal. Además, cuando la economía crece los precios tienden a elevarse dado que en general los insumos no se incrementan rápidamente.

La inmigración hace, en cierta medida, que esto último no sea una restricción. Al incrementar la oferta laboral la inmigración genera que los costos laborales tienden a mantenerse relativamente estables sin generar presiones sobre los precios, con lo cual se puede relajar el endurecimiento de la política monetaria.

\section{Conclusiones}

El estudio de los procesos migratorios adquiere especial relevancia en la actualidad, cuando las fronteras geográficas han tenido una gran apertura como resultado del desarrollo científico técnico y todo lo que trae aparejado.

Las economías nacionales sufren importantes impactos, no solo por la modificación de negocios, empresas e intercambios, sino como parte de los procesos culturales, educacionales etc., que modifican a su vez las prácticas de los individuos en los diferentes contextos. Esto se manifiesta tanto de forma positiva como de forma negativa. Es importante entonces detener la mirada en cuáles son los caminos a seguir para potenciar que los factores positivos que emergen de los procesos migratorios se potencien disminuyendo aquellos que pueden ejercer alguna influencia negativa tanto desde lo económico como desde lo cultural.

\section{Referencias bibliográficas}

Acosta Alberto, causas del reciente proceso emigratorio ecuatoriano, enero del 2003. No.3 
Becker Gary, A. Theory of Social Interaction, Journal of Political Economy, Vol. 82, pp. 10631093

Bid-fomin, receptores de remesas en Ecuador. Una investigación de mercado, mayo 2003, Pág. \# 28

Ceca, et alter. Estudio sobre las remesas envidas por los emigrantes latinoamericanos residentes en España a sus países de origen, 2002, Pág. \# 102

Cepal. Anuario de estadísticas de los países de América Latina \& el Caribe. 2003

Cepal. Panorama social de América Latina. Documento informativo. 2005

Fritz Barbara, ¿Remesas como medio estabilizador del desarrollo?, implicaciones micro y macroeconómicas para la política de remesas. Instituto de estudios iberoamericanos. Hamburgo. 2003

Orozco Manuel, Estudio de las remesas a América Latina y el Caribe: Temas y perspectivas en materia de Desarrollo, 2004, p20

Ríos Juan \& Rueda Carlos, Un estudio sobre los determinantes económicos y no económicos de los flujos de migración internacional de peruanos entre 1994-2003. 2005

Velastegui Martínez Luís, Los efectos de la migración en el Ecuador. 2004 